\title{
The routine determination of the endogenous thrombin potential, first results in different forms of hyper- and hypocoagulability
}

Citation for published version (APA):

Wielders, S., Mukherjee, M., Michiels, J., Rijkers, D. T. S., Cambus, J-P., Knebel, R. W. C., Kakkar, V., Hemker, H. C., \& Beguin, S. (1997). The routine determination of the endogenous thrombin potential, first results in different forms of hyper- and hypocoagulability. Thrombosis and Haemostasis, 77(4), 629-636. https://doi.org/10.1055/s-0038-1656024

Document status and date:

Published: 01/01/1997

DOI:

10.1055/s-0038-1656024

Document Version:

Publisher's PDF, also known as Version of record

Please check the document version of this publication:

- A submitted manuscript is the version of the article upon submission and before peer-review. There can be important differences between the submitted version and the official published version of record.

People interested in the research are advised to contact the author for the final version of the publication, or visit the DOI to the publisher's website.

- The final author version and the galley proof are versions of the publication after peer review.

- The final published version features the final layout of the paper including the volume, issue and page numbers.

Link to publication

\footnotetext{
General rights rights.

- You may freely distribute the URL identifying the publication in the public portal. please follow below link for the End User Agreement:

www.umlib.nl/taverne-license

Take down policy

If you believe that this document breaches copyright please contact us at:

repository@maastrichtuniversity.nl

providing details and we will investigate your claim.
}

Copyright and moral rights for the publications made accessible in the public portal are retained by the authors and/or other copyright owners and it is a condition of accessing publications that users recognise and abide by the legal requirements associated with these

- Users may download and print one copy of any publication from the public portal for the purpose of private study or research.

- You may not further distribute the material or use it for any profit-making activity or commercial gain

If the publication is distributed under the terms of Article $25 \mathrm{fa}$ of the Dutch Copyright Act, indicated by the "Taverne" license above, 


\title{
The Routine Determination of the Endogenous Thrombin Potential, First Results in Different Forms of Hyper- and Hypocoagulability
}

\author{
Simone Wielders' ${ }^{1}$, Manjari Mukherjee ${ }^{2}$, Jan Michiels ${ }^{3}$, Dirk T. S. Rijkers ${ }^{1}$, \\ Jean-Pierre Cambus ${ }^{4}$, Richard W. C. Knebel ${ }^{5}$, Vijay Kakkar ${ }^{2}$, H. Coenraad Hemker 1,2, \\ Suzette Béguin 1.2
}

From the 'Department of Biochemistry, Medical Faculty and Cardiovascular Research Institute, Maastricht University, The Netherlands; ${ }^{2}$ Thrombosis Research Institute, London, England; ${ }^{3}$ Clara Ziekenhuis Rotterdam, The Netherlands; ${ }^{4}$ Hôpital de Rangueil, Toulouse. France; ${ }^{5}$ Hôpital Broussais, Laboratoire d'Hémostase. Paris, France

\section{Summary}

The area under the thrombin generation curve (the endogenous thrombin potential; ETP) has been proposed as a parameter for plasmabased hypercoagulability and to monitor anticoagulant treatment. We present an ETP assay for the routine laboratory using a centrifugal analyser. Throughput is $30 \mathrm{samples} / \mathrm{h}$, within and between run imprecision is $4-5.6 \%$. Suitable substrates were developed for the ranges of $10-500 \%$ and $2-100 \%$ of normal.

Independent of tissue factor concentration (if $>4 \mathrm{pM}$ ), the normal value of the extrinsic ETP is $384.8 \pm 51.7 \mathrm{nM}$.min. The intrinsic ETP, triggered by ellagic acid, is $414 \pm 41 \mathrm{nM}$.min.

The ETP is decreased to 15 and $35 \%$ of normal by oral anticoagulation (INR 2.5-4.0) and by heparin administration (APTT 1.5-2.5 $\times$ control).

The ETP is increased in untreated subjects with congenital antithrombin deficiency and in women using oral contraceptives. In deep vein thrombosis (phlebographically confirmed), it is increased by $29.4 \%$ (extrinsic) and 53\% (intrinsic). In (angiographically assessed) coronary artery disease the increase is by $10 \%$ and $17 \%$ respectively.

\section{Introduction}

The plasma system that is responsible for the generation and subsequent inhibition of thrombin in clotting blood will cause a thrombotic tendency when producing too much free thrombin (hypercoagulability) (1); when it is not active enough (hypocoagulability) a haemorrhagic diathesis ensues. Hyper- or hypocoagulability can be brought about by a large number of different pathological conditions and there exists a large spectrum of laboratory tests to locate the underlying cause. To our knowledge, however, a single laboratory parameter that is increased in all forms of hypercoagulability and decreased in all forms of hypocoagulability does not exist. Such a variable would be useful for the detection of plasma-based thrombotic tendency and for the surveillance of drug-induced hypocoagulability (cf., blood sugar in diabetes, blood pressure in hypertension).

Correspondence to: Prof. Dr. H. C. Hemker, Maastricht University, Department of Biochemistry, P.O. Box 616, 6200 MD Maastricht, The Netherlands - Tel.: +33 43 3881675; FAX Number: +33 433670988
We have surmised before that the area under the thrombin generation curve (the endogenous thrombin potential, ETP) might be a good candidate for such a general indicator of coagulability (2-6). The key issue in proposing a new laboratory parameter for hyper- and hypocoagulation is if it is better than the standard, currently employed strategies in terms of clinical outcome. Will it minimise recurrent thrombosis and bleeding complications in the management of anticoagulation? Will it predict or indicate the occurrence of postoperative thrombosis? These questions can only be answered after extensive, large scale clinical studies that are impossible to start unless the test can be performed in the routine clinical laboratory at a sufficient throughput. Such studies are unlikely to be started unless preliminary results indicate a fair chance of success. This article describes a method for the determination of the ETP in a routine procedure and reports preliminary results in different hyper- and hypocoagulable states.

\section{Materials and Methods}

\section{Volunteers and Patients}

Eight groups of subjects were studied:

a) Apparently healthy males $(\mathbf{n}=118)$, not using drugs known to affect the coagulation system, in the ages between 18 and 80 years, (mean age \pm SD: 53.7 \pm 18.8 ) recruited from the laboratory staff, two service clubs and a monastery, served to establish the normal range.

b) Adult in-patients, 9 male and 14 female, aged 26 to 76 years (mean age \pm SD: $55.9 \pm 16.7$ ) with phlebographically confirmed active deep vein thrombosis (DVT). None of the patients was receiving anticoagulants at the time of blood sampling.

c) Patients aged 30 to 75 years, 19 male and 7 female, (mean age \pm SD: $57.0 \pm 9.3$ ) with angiographically assessed coronary artery disease (CAD) and referred for percutaneous transluminal coronary angioplasty (PTCA). None of the patients was anticoagulated, blood was obtained prior to heparin administration.

d) The control group to groups $b$ and $c$ were healthy individuals, aged 30 to 45 years, from the staff of the Thrombosis Research Institute (London, England).

e) Subjects with congenital antithrombin deficiency. Plasma from 8 patients from two families with type 1 antithrombin deficiency were tested. Diagnosis and molecular basis of the deficiency were described in detail elsewhere $(7,8)$. The thromboplastin time (PT), the activated partial thromboplastin time (APTT) before and after adding activated protein $\mathrm{C}$, the Thrombotest ${ }^{\text {te }}$ time, factors V, VII, IX, XI, XII, factor X antigen, total and free protein S, protein C 
activity and protein $\mathrm{C}$ antigen were in the nomal range (see ref. 9 for the methods employed).

f) The family members without antithrombin deficiency of group e) were used as a control group. The same determinations were done as in group e) and were found to be normal.

g) A random selection of 54 patients on long-term oral anticoagulant treatment.

h) Healthy volunteers $(n=12)$ that received unfractionated- or low-molecular-weight heparin.

\section{Materials}

Malonyl- $\alpha$-aminoisobutyryl-arginine para-nitroanilide methyl ester hydrochloride $\left(\mathrm{CH}_{3} \mathrm{O}-\mathrm{CO}-\mathrm{CH}_{2}\right.$-CO-Aib-Arg-pNA.HCl; SQ68) was synthesised by Serbio Laboratories, France (European Patent 88400304:7). The other novel chromogenic substrates were synthesised by one of the authors (D.T.S.R.) in a procedure described in detail elsewhere $(10,11)$. The chromogenic leavinggroup is always para-nitroaniline, the specific absorbency of which is $9.93 \mathrm{mOD}$ per $\mu \mathrm{M}$ per cm light-path at the measuring wavelength of $405 \mathrm{~nm}$.

A solution of Reptilase (Boehringer Mannheim, Germany) was prepared so that $20 \mu \mathrm{l}$, added to $1 \mathrm{ml}$ of plasma caused a clot in $4 \mathrm{~min}$. Ancrod, the fibrinogen clotting enzyme of the Malayan Pit Viper, was the commercial preparation Arvin $^{\circledR}$ (Knoll AG, Ludwigshafen, Germany). It was used at a final concentration of $1 \mathrm{U} / \mathrm{ml}$, causing a clotting time of $50-60 \mathrm{~s}$ in normal plasma. It has been reported not to activate clotting factors or platelets $(6,12,13)$. Protease A, a metallo-protease purified from Crotalus basiliscus venom was a kind gift of Pentapharm (Basel, Switzerland).

Thrombotest ${ }^{\text {B }}$ reagent was obtained from Nycomed Pharma AS (Oslo, Norway).

PT and APTT reagents for automated determinations (ACL 300R automaton) were rabbit-brain thromboplastin and micronised silica and purchased from Instrumentation Laboratory Limited (Milan, Italy).

Relipidated recombinant human tissue factor solution $(200 \mathrm{nM}$, a kind gift of Prof. Y. Nemerson, Mount Sinaï Medical School, New York, USA) was used as a standard. Other recombinant human tissue factor preparations were a gift of Dade Productions (Düdingen, Switzerland) as was Actin FS ${ }^{\circledR}$, a suspension of ellagic acid and soy bean phosphatides.

Tris buffer contains: $0.05 \mathrm{M}$ Tris- $\mathrm{HCl}(\mathrm{pH} 7.35), 0.1 \mathrm{M} \mathrm{NaCl}$ and $0.5 \mathrm{~g} / 1$ bovine serum albumin (BSA). Hepes buffer ( $\mathrm{pH} 7.35$ ) contains: $0.02 \mathrm{M}$ Hepes$\mathrm{NaOH}, 0.15 \mathrm{M} \mathrm{NaCl}$ and $0.5 \mathrm{~g} / \mathrm{BSA}$.

\section{Plasma}

Blood was collected on $0.13 \mathrm{M}$ trisodium citrate; nine parts of blood to one part of citrate solution. Blood was preferentially taken from fasting subjects, marked turbidity impairing the spectrophotometrical measurement. Samples were centrifuged twice at $1000 \times \mathrm{g}$, at $15^{\circ} \mathrm{C}$ for $15 \mathrm{~min}$. For the normal pool, plasma was pooled from at least 10 healthy donors, and a third centrifugation was carried out at $4^{\circ} \mathrm{C}$, for $1 \mathrm{~h}$ at $23,000 \times \mathrm{g}$. This plasma was stored at $-80^{\circ} \mathrm{C}$. It was checked that the clotting factors and the antiproteases were in the normal range.

\section{Clotting Factor Determinations}

Thrombotest ${ }^{\oplus}$ times (TT) were determined manually, after mixing $30 \mu$ l of plasma into $250 \mu \mathrm{l}$ of Thrombotest ${ }^{(0)}$ reagent. INR values were calculated as $\mathrm{INR}=\left(\mathrm{TT}_{\text {paticnt }} / \mathrm{TT}_{\text {control }}\right)^{102}$. Thrombotest percentages were read from the reference curve provided by the manufacturer.

The activated partial thromboplastin time (APTT) was determined by mixing $100 \mu \mathrm{l}$ of plasma with $100 \mu \mathrm{l}$ of Actin $\mathrm{FS}^{\circledR}$, stirring and incubating for $2 \mathrm{~min}$ at $37^{\circ} \mathrm{C}$ and recalcifying with $100 \mu \mathrm{l}$ of a $25 \mathrm{mM} \mathrm{CaCl}_{2}$ solution. The moment of clotting was determined by tilting. In patient groups $b, c$ and $d$ the PT and APTT were determined on the ACL 300R (Automated Coagulation Laboratory).

The plasma level of TAT complex was estimated by enzyme-linked immunoadsorbent assay using reagents, calibrators and controls from Behring Diag- nostics (Marburg, Germany). Besides the preassayed commercial control, a sample assayed previously was run with every batch of assays.

Prothrombin and factor $\mathrm{X}$ were measured using a one stage assay with deficient (immunodepleted) plasmas from Biopool AB (Sweden) as a reactant.

The antithrombin activities (Figs. 5 and 7) were determined by measuring the half-life time of human thrombin added to the samples and comparing it to the half-life time of thrombin in samples spiked with the international heparin standard, as in ref. 14.

The anti-factor Xa activity measurement was performed using the Rotachrom Heparin kit on the ST 888 automaton from Stago (Asnières, France).

\section{ETP Determination}

\section{A: Defibrination}

In order to allow measurement of optical density changes, samples were defibrinated with Reptilase or Ancrod. Citrated plasma was mixed with 1:50 volume of the Reptilase or Ancrod solution and incubated for $10 \mathrm{~min}$ at $37^{\circ} \mathrm{C}$, then kept on ice for $10 \mathrm{~min}$. The fibrin was wound out on a small plastic spatula. In ten patients with high fibrinogen levels $(5-8 \mathrm{mg} / \mathrm{ml})$ and in normal plasma to which up to $10 \mathrm{mg} / \mathrm{ml}$ of fibrinogen was added, this procedure proved adequate. Unlike Reptilase, Ancrod does not cause haemolysis and can be added to whole blood, rendering defibrinated plasma directly upon centrifugation. Defibrination of large series of samples is the rate limiting step of the procedure. A throughput of $30 \mathrm{samples} / \mathrm{h}$ is readily possible.

\section{B: Measurement}

The reactions are carried out in a laboratory automaton capable of measuring the course of the optical density at $405 \mathrm{~nm}$ at minimally 30 s intervals during 12 to $15 \mathrm{~min}$. We used the Cobas Bio and Cobas Fara centrifugal analysers (F. Hoffmann-La Roche, Basel, Switzerland) for most experiments. A listing of the required settings of the instruments is available from the authors. The ETP determinations on plasma during mixed anticoagulation (reported in Fig. 8) were carried out on the ACL 300R.

The reaction mixture consists of four parts of defibrinated plasma, one part of (partial) thromboplastin solution and one part of start solution. As a trigger for the extrinsic system we used recombinant thromboplastin in a concentration of about $30 \mathrm{pM}$. For the intrinsic system $1: 2.5$ diluted Actin FS ${ }^{\circledR}$ was used. In the Cobas machines the volumes were $80 \mu \mathrm{l}$ of defibrinated plasma (or $75 \mu$ l plasma with $5 \mu \mathrm{l}$ of a substance to be tested) and $20 \mu \mathrm{l}$ of the thromboplastin, without $\mathrm{Ca}^{++}$. After $30 \mathrm{~s}$ of incubation, which is sufficient for temperature equilibration, thrombin generation is started by adding $20 \mu \mathrm{l}$ of a prewarmed start solution containing $0.1 \mathrm{M} \mathrm{CaCl}_{2}$ and $3 \mathrm{mM}$ of substrate. In the ACL 300R the volumes were 1.25 times higher.

After the start of the reaction the optical density at $405 \mathrm{~nm}$ is recorded at intervals of maximally $30 \mathrm{~s}$ for at least $12 \mathrm{~min}$. Examples of the curves obtained are seen in Figs. 1 and 6. (Unless otherwise indicated all OD values are recalculated to $1 \mathrm{~cm}$ light-path.)

Carry-over between samples was tested by putting one sample of plasma to which $1 \mathrm{U} / \mathrm{ml}$ of unfractionated heparin was added in between four other samples of the same normal plasma without heparin. At this heparin concentration the ETP, as determined with SQ68, is immeasurably low, yet the normal samples located immediately after the heparin samples were not significantly lower than the other normal samples in the same run.

To measure the proportionality constant between the OD end-level (as defined in the next section) and the ETP, thrombin generation curves were also determined by subsampling according to ref. 6 . In short, from the incubation mixture given above, after starting the reaction with the $\mathrm{Ca}^{++}$solution without added substrate, $10 \mu \mathrm{l}$ samples were drawn at $30 \mathrm{~s}$ intervals in which the thrombin-related amidolytic activity was determined on S2238.

\section{C: Data handling}

The centrifugal analysers were connected to a personal computer via an installed option that makes the results available on a communication line follow- 
ing the RS-232 standard. The data are in the form of a succession of ASCII characters representing the series of OD readings, the time of the reading is given by the position in the list, knowing the sampling interval. The data is used as input for a program (Pascal or Basic), using a function for character extraction from the RS-232 interface buffer of the personal computer and transformed to a standard format file which gives the $\mathrm{OD}$ as a function of time and from which the ETP can be calculated off-line. Programs for reception-recording on IBM compatible PCs are available from the authors.

\section{D: Calculation of the substrate converted by free thrombin}

The thrombin potential cannot be read directly from the OD that develops during the experiment, because thrombin is not the only enzyme to convert the substrate. Part of the free thrombin (F) is irreversibly bound to $\alpha_{2}$-macroglobulin to form a complex $(C)$ that retains amidolytic activity. Therefore the course of OD in time that is experimentally obtained has to be split in the part due to the activity of free thrombin and the part due to the $\alpha_{2}$-macroglobulin-thrombin complex. The steady end-level of the OD-curve due to free thrombin (henceforward called OD end-level for short) is proportional to the ETP.

The experimentally obtained signal $(\mathrm{P})$ is the sum of the signals produced by free thrombin $(A)$ and by the $\alpha_{2}$-macroglobulin-thrombin complex $(B)$, so $\mathrm{P}(\mathrm{t})=\mathrm{A}(\mathrm{t})+\mathrm{B}(\mathrm{t})$. The velocity of the formation of the $\alpha_{2}$-macroglobulinthrombin complex is first order with respect to the concentration of free thrombin, so the course of its concentration is proportional to the primitive (= integrated form) of the course of free thrombin $\left(C(t)=k \int F(\tau) d \tau\right)$. If this relation holds for the course of the enzymes it also holds for the course of the OD due to the products so $B(t)=k \int A(\tau) d \tau$ and $P(t)=A(t)+B(t)=A(t)-k \int A(\tau) d \tau$. Because the sampling time is short compared to the rate of change in the curve, the integral term in this formula can be replaced by the sum of all previous A's. Consequently $P_{n}=A_{n}+k\left(A_{0}+A_{1}+\ldots \ldots .+A_{n-1}\right)$, or $A_{n}=(1-k) A_{n-1}+$ $\left(P_{n}-P_{n-1}\right)$. (Time is replaced by the sample number and the time dependent constant $\mathrm{k}$ is adapted to the sampling interval, see also below.)

The starting values of $P$ and $A$ are zero, so $A_{n}$ can be calculated from the experimental ODs (i.e. the course of $P_{n}$ ) if $k$ is known. The constant $k$ is dependent on the functional concentration of $\alpha_{2}$-macroglobulin, on the kinetic parameters of the $\alpha_{2}$-macroglobulin-thrombin complex and on the sampling interval. It is not necessary to determine $k$ experimentally. It is in the nature of the process that, from the moment on that no free thrombin is left, $A_{n}$ will not increase further. So from the time series of $\mathrm{P}$ a time series of $\mathrm{A}$ is calculated with an assumed value of $k$. This value is then varied until it renders a steady endlevel of $A$ in the end-phase of the reaction, which is the required OD end-level. A program to carry out this calculation is available from the authors.

For our normal pool the correction constant $(\mathrm{k})$ required to obtain freethrombin curves with zero end-slope was $0.288 \pm 0.012 \mathrm{~min}^{-1}, 0.29 \mathrm{~min}^{-1}$ therefore is a good starting estimate. It should be noticed however, that in the program the constant should be adapted to the sampling interval, i.e. $0.5 \times 0.29$ when this interval is $30 \mathrm{~s}$, etc.

\section{E: Calculation of the ETP from the OD end-level}

Theoretically the relation between the area under the thrombin generation curve (i.e. the ETP) and the total amount of substrate converted is given by ETP $=A \cdot K_{m} / k_{\text {cat }} .5$ (see ref. 4 ). Application of this formula requires exact knowledge of $\mathrm{K}_{\mathrm{m}}$ and $\mathrm{k}_{\mathrm{cat}}$ of the substrate in plasma. These are difficult to obtain due to the instability of thrombin in the presence of natural inhibitors. We therefore determined the proportionality between the OD end-level and the ETP by assessing the ETP independently from a thrombin generation curve obtained by subsampling.

\section{Results}

\section{Validation of the Calculation}

To validate the calculation of the OD end-level from the experimental OD we varied the concentration of active $\alpha_{2}$-macroglobulin in a

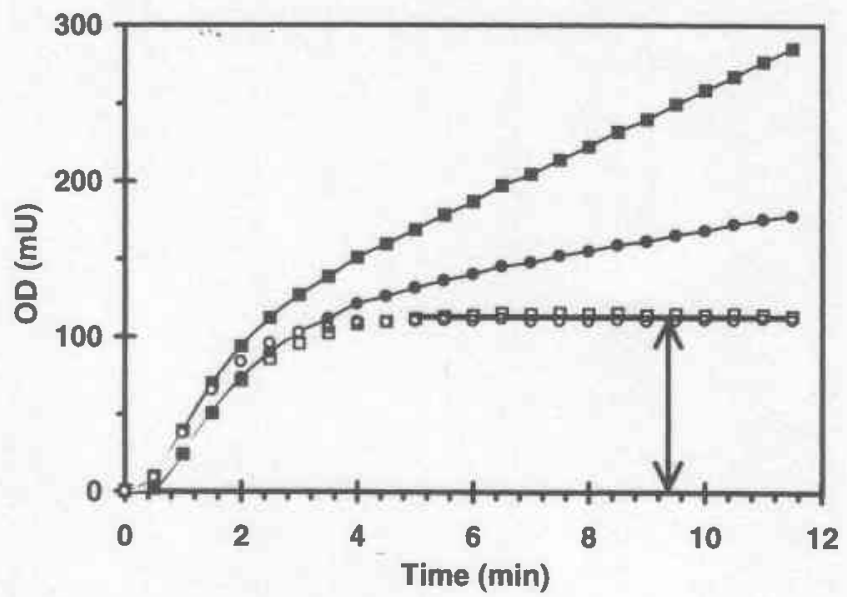

Fig. 1 Optical density traces with normal plasma, effect of $\alpha_{2}$-macroglobulin concentration. Normal pooled plasma was triggered with recombinant human thromboplastin, Msc-Val-Arg-pNA was used as the chromogenic substrate. The filled symbols are the recorded OD traces: $\mathbf{U}$ untreated normal plasma; - normal plasma incubated for $30 \mathrm{~min}$ with $1.5 \mu \mathrm{M}$ protease $\mathrm{A}$, so as to inactivate part of the $\alpha_{2}$-macroglobulin. The open symbols are the corresponding virtual $\mathrm{OD}$ traces of substrate conversion by free thrombin, calculated from the experimental curves (see Methods). The shaded line gives the mean final OD of these traces, which represents the total amount of product formed by free thrombin

plasma sample by adding protease A from Crotalus basiliscus venom, a protein that binds in a 1:1 stoichiometric complex to the inhibitor (15). In Fig. 1 it is seen that neutralisation of $1.5 \mu \mathrm{M}$ of the inhibitor significantly reduces the end-slope of the crude signal, which reflects the formation of less $\alpha_{2}$-macroglobulin-thrombin complex, but leaves the calculated course of the OD due to free thrombin, and hence the OD end-level, unaffected. Similar results were obtained when 0.5 to $3.0 \mu \mathrm{M}$ of protease $\mathrm{A}$ was added (results not shown).

\section{Selection of a Substrate}

We measured the kinetic constants of 78 newly synthesised oligopeptide $p$-nitroanilides (11) in plasma in which the natural thrombin in-

Table I Kinetic constants of chromogenic substrates used for measuring the ETP

\begin{tabular}{|c|c|c|c|c|c|c|c|}
\hline \multirow[t]{2}{*}{ No } & \multirow{2}{*}{ Substrate } & \multicolumn{3}{|c|}{ Thrombin } & \multicolumn{3}{|c|}{ Factor Xa } \\
\hline & & $\begin{array}{c}\mathrm{Km} \\
(\mu \mathrm{M})\end{array}$ & $\begin{array}{l}k_{\text {ost }} \\
\left(s^{-1}\right)\end{array}$ & RV & $\begin{array}{c}K m \\
(\mu M)\end{array}$ & $\begin{array}{l}k_{\text {exd }} \\
\left(s^{-1}\right)\end{array}$ & AV \\
\hline 1 & MZ Aib Arg pNA (SQ6B) & 830 & 046 & 1 & 3900 & 49 & 32 \\
\hline 2 & H.Val Arg pNA & 1240 & 0.23 & 0.4 & 3800 & $0^{*}$ & 0 \\
\hline 3 & Msc. Val Arg pNA & 882 & 0.79 & 1.6 & 9550 & 47 & 14 \\
\hline 4 & H Glu Gly Val.Arg pNA & 3270 & 351 & 2.9 & 1430 & 09 & 16 \\
\hline 5 & H Glu Val Arg pNA & 930 & 1.44 & 27 & 1510 & 1.1 & 13 \\
\hline 6 & DEMZ Gly Arg pNA & 870 & 1,73 & 36 & 2300 & 45 & 46 \\
\hline 7 & Boc Gly Val Arg pNA & 244 & 11.2 & 44 & 959 & 1.9 & 38 \\
\hline 8 & HD.Phe Pro Lys pNA & 35 & 90 & 486 & $>10$ & $<1$ & $<2$ \\
\hline
\end{tabular}

RV: Reaction velocity at $500 \mu \mathrm{M}$ substrate concentration, relative to thrombin action on MZ-Aib-Arg-pNA (SQ68); MZ: malonic acid monomethyl ester; DEMZ: diethyl malonic acid monomethyl ester; Msc: 2-(methylsulfonyl) ethyloxycarbonyl; Boc: tert.-butyloxycarbonyl; *) st-bstrate 2 is not hydrolysed by factor $\mathrm{Xa}$, the $\mathrm{K}_{\mathrm{m}}$ mentioned is the binding constant measured from competitive inhibition of SQ68 conversion 
Table 2 Relation between OD signal and ETP with different chromogenic substrates

\begin{tabular}{|c|l|cccl|}
\hline No & \multicolumn{1}{|c|}{ Substrate } & End level & $\begin{array}{c}\text { Substrate } \\
\text { Converted } \\
(\%)\end{array}$ & $\begin{array}{c}\text { Conversion } \\
\text { Factor }\end{array}$ & $\begin{array}{l}\text { ETP } \\
\text { Aange } \\
(\%)\end{array}$ \\
\hline 1 & MZ Aib Arg pNA (SO68) & $55.15 \pm 2.31$ & 1.12 & 6.92 & $20-1000$ \\
2 & H Val Arg pNA & $86.87 \pm 6.64$ & 1.76 & 4.39 & $12-600$ \\
3 & Msc Val Arg pNA & $108.8 \pm 7.65$ & 2,2 & 3.51 & $10-500$ \\
4 & H Glu Gly Val Arg pNA & $32.7 \pm 4.05$ & 0.66 & 11.66 & $30->1000$ \\
5 & H Glu Val Arg pNA & $168.4 \pm 4.91$ & 3.4 & 2.27 & $10-500$ \\
6 & DEMZ Gly Arg pNA & $586.6 \pm 17.4$ & 11.8 & 0.65 & $2-100$ \\
7 & Boc Gly.Val.Arg PNA \# & $(1200)$ & 50 & 0.014 & $1-50$ \\
8 & HD Phe Pro Lys pNA \# & $(13000)$ & 100 & - & $0.1-2$ \\
\hline
\end{tabular}

The first column gives the end-level of the thrombin dependent OD-signal with a normal pool plasma (mean $\pm S E M ; n=24$ or more); the second column gives the \% of the initial amount of substrate $(500 \mu \mathrm{M})$ that is converted in this process; the conversion factor (column 3 ) is the multiplier to calculate the ETP from the final OD level; the range gives the ETP values (\% of normal) that can be reliably measured with that substrate; \#: for substrates 7 and 8 , the figures for the normal values have been calculated via the catalytic efficiencies relative to SQ68

hibitors had been inactivated by heating. We selected those that were converted by thrombin at a suitable rate, that were not good factor Xa substrates and that did not inhibit prothrombin conversion. We retained those that are also split by factor $\mathrm{Xa}$, with reaction velocities similar to those of thrombin (Table 1). The peak concentrations of factor Xa in clotting plasma are below $5 \mathrm{nM}$ (16) against 100-200 nM for thrombin, so factor Xa activity will not significantly contribute to the OD signal.

We determined the ETP of normal pool plasma from the area under the thrombin generation curve, obtained in the classical way by determining the thrombin concentration in subsamples from plasma in which thrombin generates (6) and, with each of the substrates, measured the OD end-level caused by free thrombin as obtained via our standard procedure. This gave the conversion factors from OD end-level to ETP (Table 2).

Simulation experiments (results not shown) indicate that until $10 \%$ of the substrate is converted by free thrombin a linear relation between

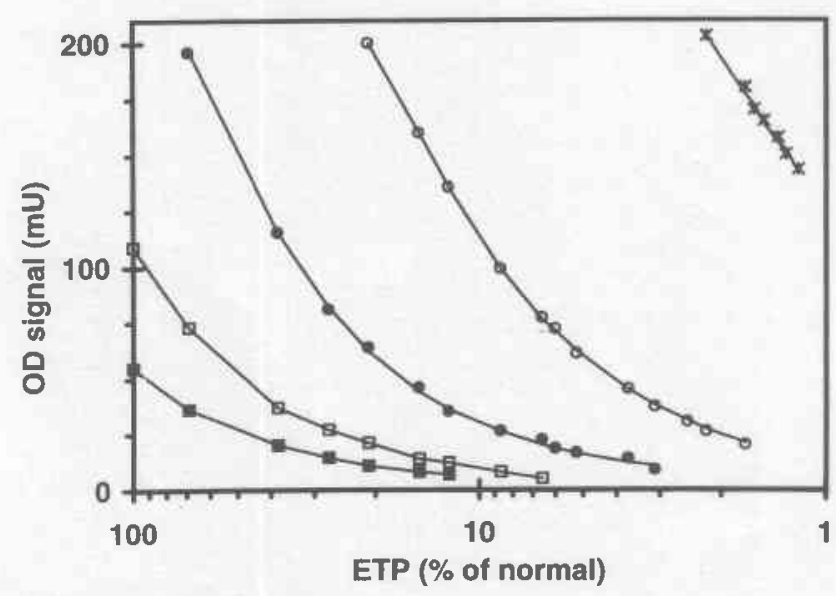

Fig. 2 OD signal with different substrates at decreasing ETP. Increasing amounts of heparin $(0-5 \mathrm{IU})$ were added to normal plasma so as to decrease the ETP. The end-levels of the thrombin-dependent signals were determined with different substrates. $\square$ : SQ 68; $\square$ : Msc-Val-Arg-pNA; O : DEMZ-Gly-ArgpNA; O: Boc-Gly-Val-Arg-pNA; X: H-D-Phe-Pro-Lys-pNA
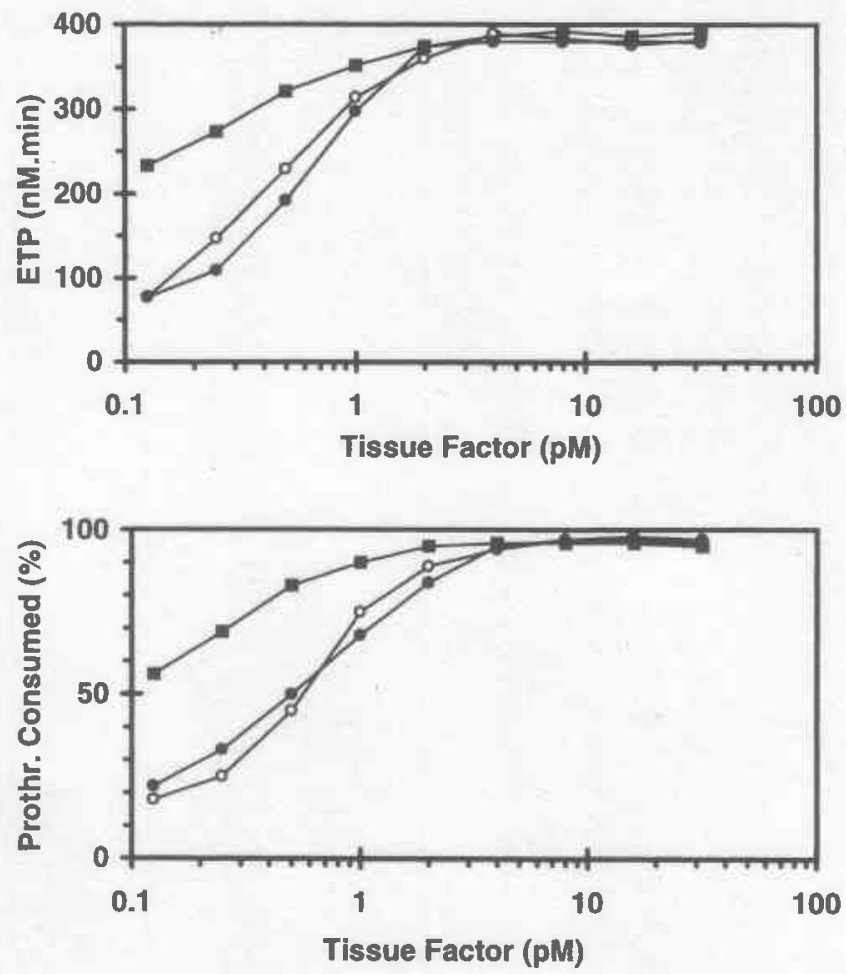

Fig. 3 Effect of thromboplastin concentration on ETP and prothrombin consumption. Upper frame (A): Relation between tissue factor concentration and ETP. Lower frame (B): Relation between tissue factor concentration and prothrombin consumption. $\square$ : Human brain thromboplastin; 0 : Recombinant thromboplastin; $\mathrm{O}$ : Recombinant thromboplastin plus $1.1 \mu \mathrm{M}$ phosphatidylserine/phosphatidylcholine (20/80)

ETP and OD end-level is for all practical purposes maintained. This sets an upper limit of $500 \mathrm{mOD}$ to the OD end-level. On the other hand under our experimental circumstances $10 \mathrm{mOD}$ is the lowest end-level that can be reliably measured. With each substrate the range of ETP values that corresponds to end-levels of 10-500 mOD is different, depending upon its kinetic properties. These ranges are shown in Table 2. Substrates 1-5 are suitable for measurements in a wide range around the normal level, whereas substrates 6 and 7 can be used to assess anticoagulation with high precision but will underestimate ETPs that are higher than normal.

We spiked normal plasma with increasing amounts of heparin, $(0-5 \mathrm{U} / \mathrm{ml})$, so as to decrease the thrombin potential over a wide range and we determined the OD end-level with the different substrates. It is seen that, depending upon their kinetic properties, each substrate gives a useful OD signal in a different range of the ETP (Fig. 2).

\section{Tissue Factor}

Fig. 3 shows the dependence of the ETP and of prothrombin consumption upon the concentration of tissue factor. Above a limit of around $3 \mathrm{pM}$, ETP and prothrombin consumption are independent of the tissue factor concentration and hardly dependent upon the type of thromboplastin used. The addition of extra phospholipid does not significantly influence the ETP. Because low amounts of tissue factor probably mimic the physiological situation best $(17,18)$, we choose as the standard condition a tissue factor concentration about twice higher than that at which, in normal plasma, prothrombin would just be maximally converted, i.e. 5 pM. In this way the test becomes virtually in- 


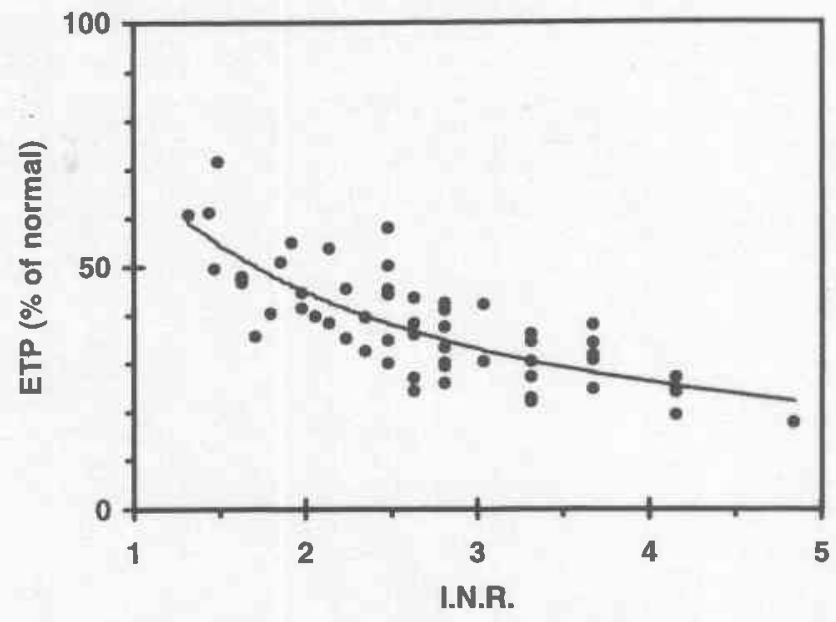

Fig. 4 The ETP in oral anticoagulation. The plasmas were from 55 randomly chosen patients on long term oral anticoagulant treatment. Recombinant human tissue factor was used as a trigger and Msc-Val-Arg-pNA as a substrate. The line represents the best fitting hyperbola $\left(R_{s}=0.778\right)$

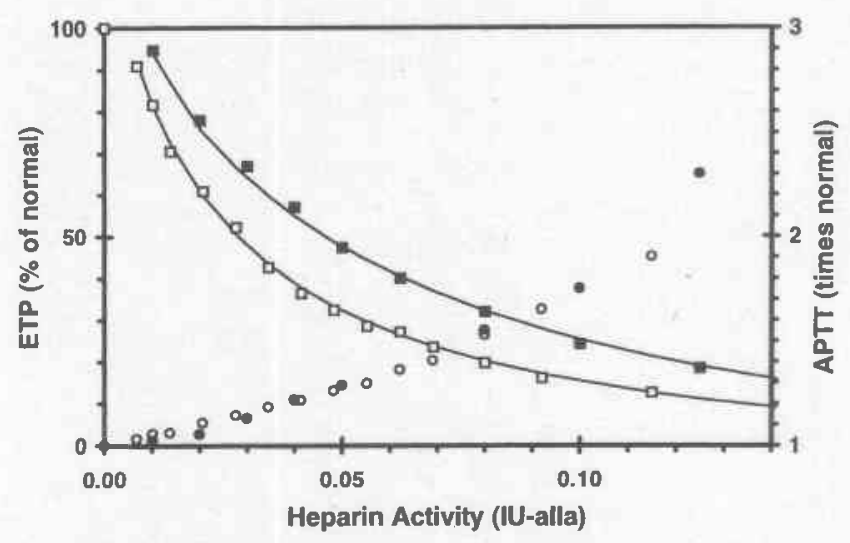

Fig. 5 Relation of inhibition of ETP and prolongation of APTT with heparin activity in vitro. To normal pool plasma different amounts of unfractionated heparin (UFH) and of a low molecular weight heparin (LMWH) were added. The ETP and APTT were determined and plotted against the anti-thrombin activity of the heparin. $\square$ : ETP, low molecular weight heparin; $\square$ : ETP, unfractionated heparin; : APTT, LMWH; O: APTT, UFH

dependent of changes in the activity of the thromboplastin. A number of different thromboplastin preparations gave identical results (results not shown).

\section{Normal Values}

Under our experimental conditions, plasmas from normal donors were found to give an OD end-level of $54.8 \pm 8.1 \mathrm{mOD}(\mathrm{n}=118)$ from SQ68 and 108.1 $\pm 16.8 \mathrm{mOD}(\mathrm{n}=84)$ from Msc-Val-Arg-pNA. With the conversion constants of Table 2 , this represents an endogenous thrombin potential of $384.8 \pm 51.7 \mathrm{nM} . \mathrm{min}$ and $394.3 \pm 62.3 \mathrm{nM}$.min respectively. The normal value of the ETP in the intrinsic system appears not significantly higher: $414 \pm 41 \mathrm{nM}$.min (SQ68).

The within run imprecision of the determination, i.e. the standard error of a single value calculated from 20-24 identical samples determined in the same run on a Cobas instrument, was about $4 \%$. (extrinsic $3.5 \%$, intrinsic $4.4 \%[\mathrm{n}=22]$ ). The between run imprecisions, obtained

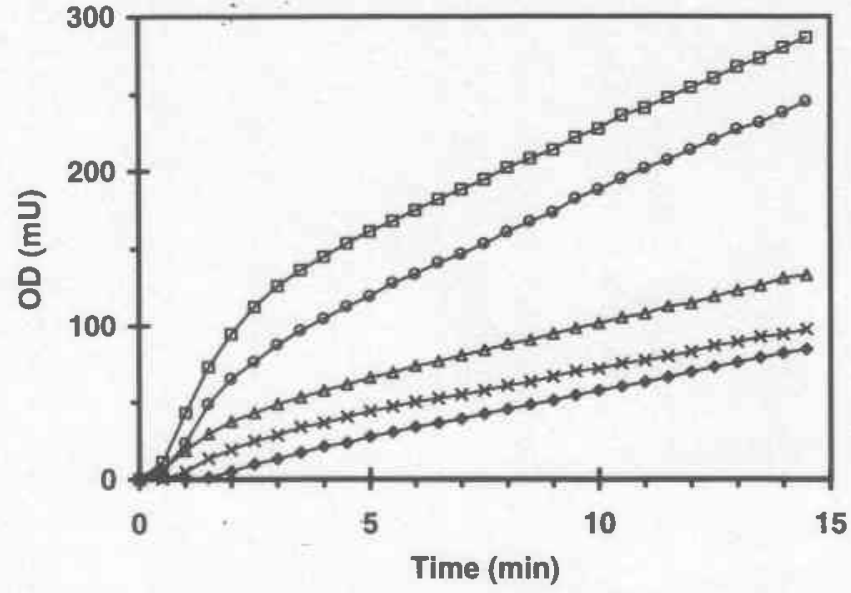

Fig. 6 Optical density traces in samples after heparin injection. The plasmas were from a volunteer after subcutaneous injection of $1 \mathrm{mg}$ of Enoxaparin per $\mathrm{kg}$ body weight $(72 \mathrm{mg})$. Graphs in descending order: zero time, $12 \mathrm{~h}, 8 \mathrm{~h}$, $1.5 \mathrm{~h}$ and $3 \mathrm{~h}$ after injection. Msc-Val-Arg-pNA was used as the chromogenic substrate

when the same normal plasma was tested in different runs on different days, was on the mean $1 \%$ higher: (extrinsic system $4.7 \%$, intrinsic $5.6 \%[\mathrm{n}=58])$.

Hepes buffer and Tris buffer give the same normal ETP value in the extrinsic system (403.8 nM.min \pm 12.4 versus 398.4 nM.min \pm 14.1 ; $\mathrm{n}=17, \mathrm{SQ68})$, in the intrinsic system Hepes buffer may give slightly lower values than Tris buffer $(399.0 \pm 10.5 \mathrm{nM}$.min versus 435.2 $n M \cdot \min \pm 16.6 ; n=17$, SQ68).

\section{The ETP in Anticoagulant Treatment}

In Fig. 4 we compare the ETP with the INR value in patients under long-term anticoagulation. The ETP decreases with increasing INR, the correlation between ETP and INR is not rectilinear and relatively loose (see discussion).

Fig. 5 shows the effect on the APTT and the ETP of increasing concentrations of heparin added to normal pooled plasma. The ETP is sensitive to low concentrations of heparin, whereas the APTT is not. Fig. 6 gives the OD traces obtained at different intervals after subcutaneous injection of $1 \mathrm{mg} / \mathrm{kg}$ of Enoxaparin, significant reduction of the signal is still observed $12 \mathrm{~h}$ after injection. Fig. 7 shows a plot of the inhibition of the ETP versus anti-thrombin activity in a series of ex vivo samples after subcutaneous injection of unfractionated- and low-molecularweight heparin. Comparison of the ex vivo data with the in vitro data of Fig. 5 shows that unfractionated heparin induces an extra anticoagulant effect that is not accounted for by the heparin activity per se (see Discussion)

In Fig. 8 the ETP is compared to the relevant data obtained from the routine laboratory tests in a patient that was admitted with deep venous thrombosis and in which treatment with the low molecular weight heparin Fraxiparine was followed by oral anticoagulant treatment. Similar pictures were seen in 5 other patients, treated with unfractionated heparin or low molecular weight heparin. Unlike the conventional tests, the ETP is seen to reflect the combined effect of both anticoagulants.

\section{The ETP in Thrombotic Tendency and Manifest Thrombotic Disease}

We determined the ETP in 8 patients with a thrombotic tendency due to antithrombin deficiency, belonging to two well documented families 


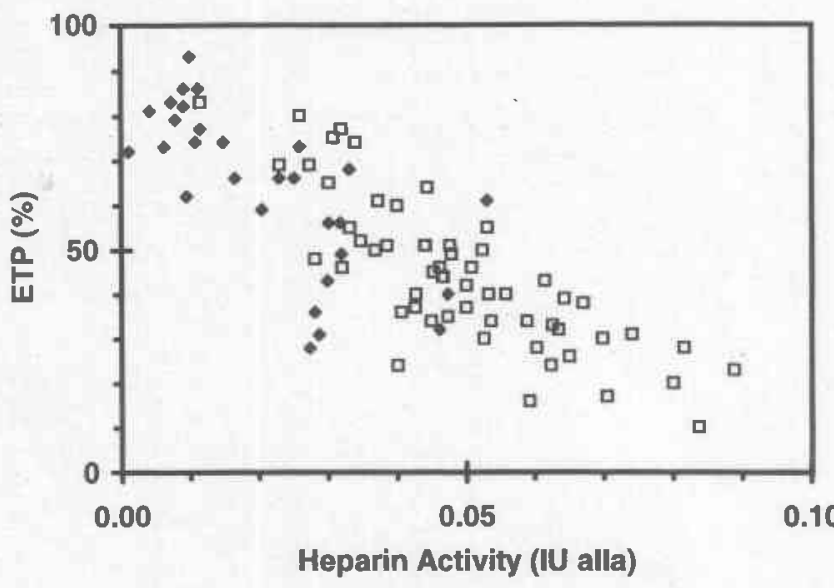

Fig. 7 Inhibition of ETP upon enoxaparin administration. The ETP of samples obtained after subcutaneous heparin administration is plotted versus antithrombin activity, expressed in IU. $\square$ : $\mathrm{LMWH}\left(\mathrm{R}_{\mathrm{s}}=0.816\right) ; \diamond: \mathrm{UFH}$ $\left(R_{s}=0.769\right)$

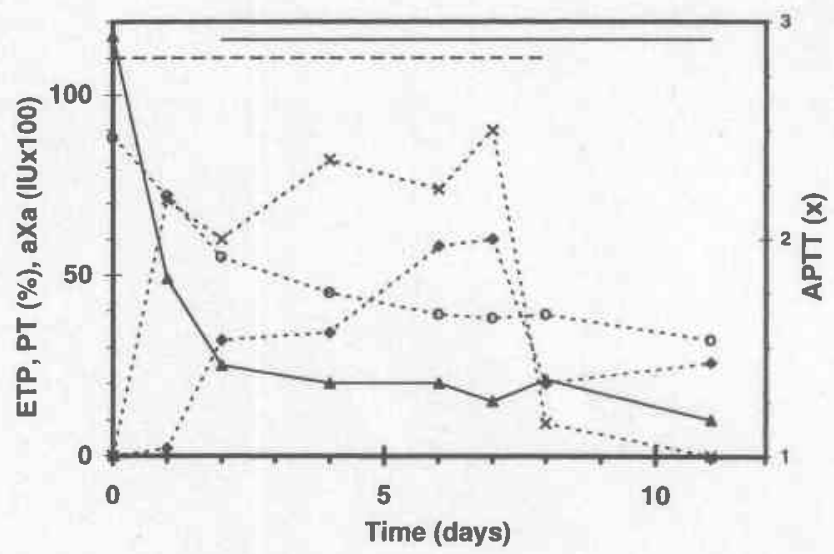

Fig. 8 The course of ETP, PT, APTT and anti-factor Xa activity during mixed anticoagulant treatment. Dashed line: Period of heparin administration (Fraxiparine, s.c. twice daily, 92 IU anti-factor Xa activity per $\mathrm{kg}$ body weight, adjusted dosages so as to keep the anti-factor Xa measurement between 0.5 and $1.0 \mathrm{IU} / \mathrm{ml}$ ). Drawn line: Period of oral anticoagulation. (Préviscan at an initial dosage of $20 \mathrm{mg}$, and adjusted so as to obtain a PT between 30 and $50 \%$, corresponding to an INR of 2.0 to 3.5 ). $\bigcirc:$ PT; $:$ APTT; $\Delta$ : ETP; $X$ anti-factor Xa activity

$(7,8)$, before prophylaxis by anticoagulation was started (Table 3 ). The ETP is significantly increased, roughly proportional to the decrease of the antithrombin-level.

We also collected plasmas, before anticoagulant therapy was given, from patients presenting with deep vein thrombosis (DVT) and acute

Table 3 ETP in antithrombin deficiency

\begin{tabular}{|l|cc|}
\hline & Patients $(n=8)$ & Controls $(n=9)$ \\
\hline ETP Extrinsic (\%) & $146.8 \pm 17.5$ & $104.7 \pm 16.7$ \\
ETP Intrinsic (\%) & $143.9 \pm 14.7$ & $107.8 \pm 19.6$ \\
AT III (\%) & $61.5 \pm 3.0$ & $96.9 \pm 3.8$ \\
F.11 (\%) & $100.1 \pm 4.1$ & $106.9 \pm 12.7$ \\
Factor X (\%) & $102.5 \pm 6.8$ & $103.3 \pm 19.2$ \\
\hline
\end{tabular}

Table 4 ETP, PT, APTT and TAT-complexes in patients with deep vein thrombosis and coronary artery disease

\begin{tabular}{|c|c|c|c|c|c|c|}
\hline Group & number & $\begin{array}{c}\text { ETP } \\
\text { Extrinsic } \\
\text { (nu.min) }\end{array}$ & $\begin{array}{c}\text { ETP } \\
\text { Intrinsle } \\
\text { (nMmin) }\end{array}$ & $\begin{array}{l}\text { PT } \\
\text { (sec) }\end{array}$ & $\begin{array}{l}\text { APT } \\
\text { (sec) }\end{array}$ & $\begin{array}{c}\text { TAT } \\
\text { Complox } \\
(\mu g / m l)\end{array}$ \\
\hline $\begin{array}{r}\text { Control } \\
(\%)\end{array}$ & 28 & $\begin{array}{c}3543 \pm 10.7 \\
100 \pm 3\end{array}$ & $\begin{array}{c}325.5 \pm 409 \\
100 \pm 13\end{array}$ & $12,7 \pm 0.1$ & $33,4 \pm 07$ & $3.1 \pm 0.2$ \\
\hline $\begin{array}{l}\text { DVT } \\
\text { (\%) }\end{array}$ & 21 & $\begin{array}{c}458.5 \pm 28.3 \\
129 \pm 8\end{array}$ & $\begin{array}{c}498.2 \neq 46.5 \\
153 \pm 14\end{array}$ & $12,8 \pm 03$ & $335 \pm 0.9$ & $12.0 \pm 1.7$ \\
\hline $\begin{array}{l}\text { CAD } \\
\text { (\%) }\end{array}$ & 31 & $\begin{array}{c}390.0 \pm 12.6 \\
110 \pm 4\end{array}$ & $\begin{array}{c}382.0 \pm 11.3 \\
117 \pm 4\end{array}$ & $12.9 \pm 0.1$ & $32.1 \pm 0.9$ & $3.7 \pm 0.5$ \\
\hline
\end{tabular}

The results are expressed as mean \pm SEM; Mann-Whitney U-test was used to compare the group means of the patients to the control; for the values indicated in bold a two-tailed $\mathrm{p}$-value of $<0.0001$ was found and considered to indicate a significant difference

coronary artery disease (CAD) and in which the diagnosis was later confirmed by phlebography and coronary angiography. The ETP triggered via the extrinsic or the intrinsic pathway is significantly elevated in both conditions (Table 4). The rise being more pronounced in DVT than in CAD. Neither the PT nor the APTT reflects this change in the coagulation system. The mean TAT level, a marker for thrombin generation in vivo, is significantly increased in the DVT group only.

\section{Discussion}

\section{The ETP and Clotting Tests}

The method presented opens the possibility to assess the area under the thrombin generation curve (endogenous thrombin potential, ETP) in the routine haematological laboratory. The ETP represents the amount of functional thrombin that is transiently present during the plasmato-serum conversion and therefore is an overall test of the final result of the combined activities of the procoagulant- and anticoagulant factors in the plasma. This prompts the question of how it compares to the PT and the APTT as an overall test of coagulability. Clotting occurs at the moment that about $1 \%$ of the plasma prothrombin is converted into thrombin [about $10 \mathrm{nM}$, or 1 international unit (2)]. All fibrinogen is then split in a matter of seconds. So the clotting time represents the lagphase before thrombin appears and $>90 \%$ of thrombin is formed after the moment of clotting. There is not automatically a close correlation between the duration of the lag-phase and the amount of thrombin that develops. Heparin treatment e.g. will not influence the clotting-time in the extrinsic system but quite efficiently diminishes the amount of thrombin appearing (19). Antithrombin deficiency does not cause significant shortening of PT or APTT (cf. 7,8).

Unlike clotting times, the ETP reflects not only the first part but the whole process of thrombin generation and inactivation. In vivo, thrombin, by diffusion and convection, will spread around the site of its formation. The amount of thrombin formed will determine the extent of haemostatic- and thrombotic reactions in the neighbourhood. Also the amount of thrombin generating in a forming clot determines its resistance to clot lysis $(20,21)$. We therefore think that the total amount of thrombin formed is a more relevant parameter than the lag-time of its formation. 
The precise relation between the value of the ETP and the levels of the different pro- and anticoagulant factors in the plasma remains to be investigated. Due to the intricate non-linear kinetics of the coagulation system this relation is necessarily a complicated one. Preliminary studies show that the amount of prothrombin converted and the potency of the antithrombins are major determinants. Ongoing studies show that the concentrations of the factors II, V, VII, VIII, IX and XI play a role as well as that of the factors of the APC-system and the anti-thrombins. In the present study we limit ourselves to showing the feasibility of a clinical function test based upon the ETP measurement and its correlation with clinical conditions, without a further attempt at functional interpretation.

\section{The ETP in Anticoagulation}

The data in Figs. 4-8 show that the ETP is lowered by oral anticoagulation, by heparin as well as by mixed treatment (Fig. 8). The ETP is also diminished by addition to normal plasma of hirudin, dermatan sulphate, lactobionic acid and other irreversible inhibitors (results not shown). So far the ETP seems to be an indicator of any anticoagulant effect.

Comparing ETP values with INR values (Fig. 4), it is seen that the correlation between ETP and INR is obviously non-linear and relatively loose [Spearman rank correlation coefficient $\left(r_{s}\right)=0.778$ ]. Adequate anticoagulation (INR 2.5-4.0) corresponds to $65-85 \%$ inhibition of the ETP. The essential question of whether the INR or the ETP, is the better predictor of bleeding and/or rethrombosis will require a clinical trial.

In Fig. 5 the dose response curves of the ETP and the APTT are shown in normal plasma spiked with increasing doses of heparin. A prolongation of 1.5 to 2.5 of the APTT, which is thought to represent adequate anticoagulation, again corresponds to $65-85 \%$ inhibition of the ETP. It thus seems that the ranges of anticoagulation, determined in clinical practice with two different drugs and with two different methods of control, induce similar ETP values.

Unlike current tests, the ETP is sensitive to low levels of anticoagulation; e.g. the effect of $1 \mathrm{mg} / \mathrm{kg}$ Enoxaparin is still detected $12 \mathrm{~h}$ after subcutaneous injection (Fig. 6, cf. 14). Both for coumarin congeners and for heparin it has been claimed that low levels of anticoagulation, not or hardly influencing PT and APTT, do prevent thrombosis (see ref. 22 for a discussion). Probably such medication will affect in the ETP.

The APTT, being sensitive to variations of heparin activity in the high concentration range, might theoretically serve a useful alarm-function for over-anticoagulation. Clinical experience however shows that it does not $(23,24)$. The explanation is probably that the APTT is difficult to relate to coagulation factor inhibition (25) and resists straightforward standardisation (26). Whether the ETP will be better again requires a clinical trial.

The inhibition of the ETP after subcutaneous injection of unfractionated (UFH)- and low-molecular-weight heparin (LMWH) is plotted against an indicator of heparin concentration (anti-thrombin activity) in Fig. 7. The strict curvilinear relation between ETP-inhibition and heparin activity that is found in vitro (Fig. 5) is lost $\left(R_{s}=0.769\right.$ for UFH and 0.816 for LMWH), indicating that the individual anticoagulant response is not determined by the heparin activity alone. After injection of LMWH the inhibition of the ETP found in vivo scatters around the in vitro values, after injection of UFH there is an excess inhibition of the ETP in vivo, possibly caused by the release of tissue factor pathway inhibitor $(27,28)$. If the ETP values are plotted against the anti-factor Xa activity of the plasma samples (expressed in conventional units) similar correlation coefficients are found. Because the anti-factor Xa activity, expressed in I.U. in the conventional way, is about twice overestimated, the UFH points are spread over about double the heparin activity range (i.e. 0-0.2 IU), erroneously suggesting the LMWH to be less active than UFH when plotted on this basis. (see refs 29 and 30 for a discussion of this phenomenon).

In clinical practice three different tests are used in anticoagulant treatment: PT for oral anticoagulation, rendered as the INR (31), APTT for both unfractionated and low-molecular-weight heparin (32) and anti-factor Xa activity for low molecular weight heparins (33). This hampers the control of mixed heparin- and oral-anticoagulant therapy. Fig. 8 shows that the ETP reflects the combined effect of both therapies, whereas the routine laboratory values react primarily to one or the other of the treatments.

\section{The ETP in Thrombosis Prone States and Thrombotic Disease}

Congenital antithrombin deficiency evidently causes an elevated ETP (Table 3). It has been shown that the ETP measured as the area under the (manually obtained) thrombin generation curve, is increased in women using oral contraceptives but not suffering from thrombosis (34). In a preliminary report using the continuous method here described, it is stated that oral contraceptives of three different doses and types given to 25 healthy volunteers increases the (extrinsic) ETP to $121 \%$ of the baseline value, independent of the type of contraceptive. This increase was accompanied by a significant increase of the fibrinopeptide A levels (35). We could confirm the increase of the ETP in women using oral contraceptives (results not shown). It seems that the ETP may indeed signal a thrombotic tendency.

It should be noted that there exists a fundamental difference between the ETP, which shows the potential capacity of the plasma to generate thrombin, and markers of in vivo thrombin generation like TAT complexes and $\mathrm{Fl}+2$, which show that the mechanism is indeed triggered in the patient. A healthy child with antithrombin (III) deficiency e.g. will show a significantly increased ETP but near to normal F1+2 values. An otherwise normal subject with a beginning thrombotic process may show increased TAT and F1+2 levels but near to normal ETP values.

The data on patients with DVT and CAD show that the ETP is above normal in the plasma of patients with an active thrombotic process, be it arterial or venous, than in normal controls. This might represent either a pre-existing tendency of these plasmas to generate more thrombin - which condition then caused, or contributed to, the disease - or it might reflect changes brought about in the circulating plasma by the disease process, the two explanations by no means being mutually exclusive. The high level of TAT complexes found in DVT patients (Table 4), shows that the circulating blood has been exposed to thrombin-activity. Given the positive feedback effects of thrombin on thrombin generation (3,19 and references therein), it is likely that this in itself enhances the thrombin generating power of the blood. This latter explanation may be less likely in the case of CAD, where no elevated TAT complexes are found. Clinical and epidemiological studies will have to show in how far an increased ETP indeed indicates an increased thrombotic risk and in how far it is augmented by an ongoing thrombotic process.

We conclude that with the present technique the ETP may be determined in the clinical routine laboratory and that the limited data available justify more extensive studies on the suitability of the ETP measurement as a general indicator of anticoagulation on the one hand and as a screening procedure for hypercoaguable states on the other. 


\section{Acknowledgements}

We are grateful to professors J. N. Fiessinger, M. Aïach and Dr. D. Vitoux, Hôpital Broussais (Paris, France), for their help with the study on patients with mixed anticoagulant treatment. We thank Barry Woodhams of Dade Productions (Duidingen, Switzerland) for helpful suggestions and for reading and commenting the manuscript. Prof. Dr. P. W. Hemker of the Mathematical Centre Amsterdam (The Netherlands) we thank for his help with the mathematical aspects of this work.

\section{References}

1. Virchow R. Gesammelte Abhandlungen zur Wissenschaftlichen Medizin. Berlin: Max Hirsch Verlag 1962; pp 294.

2. Biggs R, Macfarlane RG. Human Blood Coagulation and its Disorders. Oxford: Blackwell Scientific Publications 1967; pp 67.

3. Hemker HC. Thrombin Generation, an Essential Step in Haemostasis and Thrombosis. In: Bloom AL, Forbes CD, Thomas DP, Tuddenham EGD (eds). Haemostasis and Thrombosis. Edinburgh: Churchill Livingstone 1993; pp 477-90.

4. Hemker HC, Wielders SJH, Kessels H, Béguin S. Continuous registration of thrombin generation in plasma, Its use for the determination of the thrombin potential. Thromb Haemost 1993; 70: 617-24.

5. Hemker HC, Béguin S. Thrombin generation in plasma: its assessment via the endogenous thrombin potential. Thromb Haemost 1995; 74: 134-8.

6. Hemker HC, Willems GM, Béguin S. A computer assisted method to obtain the prothrombin activation velocity in whole plasma independent of thrombin decay processes. Thromb Haemost 1986; 56: 9-17.

7. Jochmans K, Lissens W, Ting Yin, Michiels JJ, Van der Luit L, Peerlinck K, De Waele M, Liebaers I. Molecular basis for type 1 antithrombin deficiency: Identification of two novel point mutations and evidence for a de novo splice site mutation. Blood 1994; 84: 3742-8.

8. Michiels JJ, Van der Luit L, Van Vliet HHDM, Jochmans K, Lissens W. Nonsense mutation Arg197 stop in a dutch family with type 1 hereditary antithrombin deficiency causing thrombophylia. Thromb Res 1994; 78: 251-6.

9. Engel H, Zwang L, Van Vliet HHDM, Michiels JJ, Stibbe J, Lindemans J. Phenotyping and genotyping of coagulation factor $\mathrm{V}$ Leiden. Thromb Haemost 1996; 75: 267-8.

10. Rijkers DTS, Adams HPHM, Hemker HC, Tesser GI. A convenient synthesis of amino acid $p$-nitroanilides, synthons in the synthesis of protease substrates. Tetrahedron 1995; 51: 11235-50.

11. Rijkers DTS, Wielders SJH, Tesser GI, Hemker HC. Design and synthesis of thrombin substrates with modified kinetic parameters. Thromb Res 1995; 79: 491-9.

12. Chan KE, Rizza CR, Henderson MP. A study on the coagulant properties of Malayan pit-viper venom. Br J Haemat 1965; 11: 646-57.

13. Davey MG, Luscher EF. Actions of some coagulant snake venoms on blood platelets. Nature 1965; 207: 730.

14. Bendetowicz AV, Béguin S, Caplain H, Hemker HC. Pharmacokinetics and pharmacodynamics of a low molecular weight heparin (Enoxaparin) after subcutaneous injection, comparison with unfractionated heparin. A three way cross over study in human volunteers. Thromb Haemost 1994; 71 : 305-13.

15. Svoboda P, Meier J, Freyvogel TA. Purification and characterisation of the $\alpha_{2}$-antiplasmin and $\alpha_{2}$-macroglobulin inactivating enzymes from the venom of the mexican west coast rattlesnake (Crotalus basilicus). Toxicon 1995; 33: 1331-46.
16. Lindhout T, Blezer R, Hemker HC. The anticoagulant mechanism of action of recombinant hirudin (CGP 39393) in plasma. Thromb Haemost 1990; 64: 464-8.

17. Nemerson Y. Tissue factor, then and now. Thromb Haemost 1995; 74: 180-4.

18. Morissey JH. Tissue factor modulation of factor VII avtivity. Thromb Haemost 1995; 74: 185-8.

19. Béguin S, Lindhout T, Hemker HC. The mode of action of heparin in plasma. Thromb Haemost 1988; 60: 457-62.

20. Von dem Borne PAKr, Meijers JCM, Bouma BM. Feedback activation of Factor $\mathrm{XI}$ in plasma results in additional formation of thrombin that protects fibrin clots from fibrinolysis. Blood 1995; 86: 3035-42.

21. Bajzàr L, Manuel R, Nesheim ME. Purification and characterization of TAFI, a thrombin-activatable fibrinolysis inhibitor. J Biol Chem 1995; 270: 14477-84.

22. Barrowcliffe TW, Johnson EJ, Thomas DP. Low Molecular Weight Heparin. Chichester: John Wiley \& Sons 1992; pp 135.

23. Levine NM, Hirsh J, Gent M, Turpie AG, Cruickshank M, Weitz J, Anderson D, Johnson M. A randomized trial comparing activated thromboplastin time with heparin assay in patients with acute venoembolism requiring large daily doses of heparin. Arch Intern Med 1994; 154: 49-56.

24. Hull RD, Raskob GE, Rosenbloom D, Lemaire J, Pineo GF, Bayliss B, Ginsberg JS, Panju AA, Brill-Edwards P, Brant R. Optimal therapeutic level of heparin therapy in patients with venous thrombosis. Arch Intern Med 1992; 152: 1589-95.

25. Burns ER, Goldberg SN, Wenz B. Paradoxic effect of multiple mild coagulation factor deficiencies on the prothrombin time and activated partial thromboplastin time. Am J Clin Path 1993; 100: 94-8.

26. Van der Velde EA, Poller L. The APTT monitoring of heparin - The ISTH/ ICSH Collaborative study. Thromb Haemost 1995; 73: 73-81.

27. Sandset PM, Abildgaard U, Larsen ML. Heparin induces release of extrinsic coagulation pathway inhibitor (EPI). Thromb Res 1988; 50: 803-13.

28. Sandset PM, Abildgaard U. Extrinsic pathway inhibitor - the key to feedback control of blood coagulation initiated by tissue thromboplastin. Haemostasis 1991; 21: 219-39.

29. Hemker HC, Béguin S. Standard- and Method Independent Units for Heparin Anticoagulant Activities. Thromb Haemost 1993; 70: 724-8.

30. Hemker HC, Béguin S. The Activity of Heparin in the Presence and Absence of $\mathrm{Ca}^{++}$Ions; why the Anti-Xa Activity of LMW Heparins Is about two Times Overestimated. Thromb Haemost 1993; 70: 717-8.

31. Van den Besselaar AMHP. Recommended method for reporting therapeutic control of oral anticoagulant therapy. Thromb Haemost 1990; 63: 316-7.

32. Hirsh J. Optimal Therapeutic Ranges for Unfractionated Heparin and Low Molecular Weight Heparins. In: Fuster V, Verstraete M (eds). Thrombosis in Cardiovascular Disorders. Philadelphia: W. B. Saunders 1992; pp 147.

33. Aiach M, Michaud A, Capron L, Fiessinger JN. Determination of factor X and heparin with chromogenic substrate. Acta Chir Scand Suppl 1982; 509: 109-13.

34. Rotteveel RC, Roozendaal KJ, Eijsman L, Hemker HC. The influence of oral contraceptives on the time-integral of thrombin generation (Thrombin Potential). Thromb Haemost 1993; 70: 959-62.

35. Berends F, Morriën-Salomons WM, Van Enk A, Béguin S, Van den Ende A. Oral contraceptives induce the prethrombotic state. Thromb Haemost 1995; 73: 959 (abstr).

Received August 30, 1996 Accepted after resubmission December 3, 1996 